\title{
Regeneration Characteristics and Spatial Pattern of Platycladus orientalis in Mount Tai, China
}

\author{
Wenhui Li ${ }^{1,2^{*}}$, Xiyue Zhao ${ }^{1 *}$, Jinli Bian ${ }^{1,3}$, Ruiqiang Liu', Ruiqiang Ni ${ }^{1 \#}$ \\ ${ }^{1}$ College of Forestry, Shandong Agricultural University, Tai'an, China \\ ${ }^{2}$ College of Forest, Beijing Forestry University, Beijing, China \\ ${ }^{3}$ Administration of Natural Resources, Dezhou, China \\ Email: "wind0309@163.com
}

How to cite this paper: Li, W.H., Zhao, X.Y., Bian, J.L., Liu, R.Q. and Ni, R.Q. (2021) Regeneration Characteristics and Spatial Pattern of Platycladus orientalis in Mount Tai, China. Open Journal of Ecology, 11, 276-286.

https://doi.org/10.4236/oje.2021.113020

Received: February 10, 2021

Accepted: March 9, 2021

Published: March 12, 2021

Copyright ( 2021 by author(s) and Scientific Research Publishing Inc. This work is licensed under the Creative Commons Attribution International License (CC BY 4.0).

http://creativecommons.org/licenses/by/4.0/ (c) (i) Open Access

\begin{abstract}
Platycladus orientalis is one of the main tree species in Mount Tai, and its sustainable development is of great significance to the protection and development of the forest ecological environment of Mount Tai. In this study, a representative sample plot of Platycladus orientalis with a size of $30 \mathrm{~m} * 20 \mathrm{~m}$ was selected on Mount Tai. The growth and distribution of the parent trees and seedlings of Platycladus orientalis were investigated in the sample plots. The results showed that both the mother cypress trees and seedlings inside the plot present an aggregated distribution pattern within a certain scale, which conforms to the distribution of most natural communities; and the mother cypress can promote seedlings within a certain scale. Although Platycladus orientalis has good natural regeneration ability, it is difficult to succeed in understory regeneration solely relying on natural fertility, and it is not conducive to the long-term stable development of forest stands. Therefore, the thinning of Platycladus orientalis and the adjustment of the forest stand structure and artificial promotion of natural regeneration can not only reduce operating costs, but also conform to the idea of forest near-natural management and maintain sustainable forest development.
\end{abstract}

\section{Keywords}

Platycladus orientalis, Understory Regeneration, Point Pattern Analysis, Community Structure, Intraspecific Relationship

\section{Introduction}

Natural regeneration is a natural biological process of forest resource reproduc${ }^{\star}$ Contributed equally to this work. 
tion. It has an important impact on the productivity of forest ecosystems, the structure of forest communities and their biological diversity in the future, and is the most important link in the process of implementing sustainable forest management [1] [2]. The factors for the success of natural regeneration are as follows: one is the number of seeds with germination ability on the forest land, the second is the forest environment that meets the germination requirements, and the third is the growth environment of seedlings. In the early stage of seedling growth, seedlings often die due to unstable growth environment. Fourth, the environment change after seedlings becoming saplings in the late growth stage. The density of competing plants has an important influence on whether the saplings can grow healthily [3]. Only when all conditions are fully adapted can we successfully guarantee the natural regeneration of forests. But in reality, the natural regeneration of forests is always unsatisfactory. In order to strengthen forest management and make it rapidly renew and grow successfully, it is necessary to take measures to artificially promote natural regeneration to achieve greater functioning of the forest.

Natural regeneration can not only reduce the cost of regeneration, but also contribute to the sustainability of development benefits and the protection of community stability [4]. The influencing factors for seed germination and survival growth of seedlings not only include factors such as soil moisture and altitude, but the influence of other plants in the growth environment on Platycladus orientalis (PO) seedlings. The growth of the parent trees has an impact and effect on the survival of seedlings. The competition between species and species for space and resources forms competition, which has an impact on the survival and development of individual plants, and further affects the community structure and stability and species diversity [5]. To maintain a reasonable community structure to maintain its functions, protect its biodiversity, and promote the evolution and development of community structure, it is necessary to investigate and study intra-species and inter-species competition [6], so as to achieve the purpose of coordinating their competitive relationship.

Platycladus orientalis (Platycladus orientalis) is an evergreen tree of the $\mathrm{Cu}$ pressaceae family. It is one of the most widely used ornamental trees in China. As a light-loving tree species, Platycladus orientalis has strong adaptability to poor site condition and low requirements for soil conditions. Cypress grows on flat land or on cliffs, and is suitable as a tree species in the barren and dry areas of rocky mountains. One of the central distribution areas of Platycladus orientalis is Shandong Province. It is often distributed below $900 \mathrm{~m}$ altitude in Shandong Province. Platycladus orientalis has strong germination ability and shallow root system. It has the characteristics of a large number of plantings and good natural regeneration ability, but the forests it forms are mostly single-layered forests of the same age, which cannot form complex and stable multi-layer mixed forests. However, it is always difficult for seedlings to survive under natural canopy. It is still unrealistic to rely only on pure natural forces to regenerate forests. The research work carried out on Platycladus orientalis in Mount Tai in- 
cludes: the distribution of regeneration saplings under Platycladus orientalis plantations and the influence of canopy closure, slope direction and soil nutrient on regeneration. The research results showed that under certain conditions, areas with low altitude and good sunlight have more regeneration.

To formulate a better forest management plan, we need to conduct a detailed analysis of the factors affecting the success of natural regeneration, so as to adapt measures to local forest conditions. Therefore, studying the regeneration of Platycladus orientalis seedlings and its influencing factors is of great significance to promote the natural regeneration of Platycladus orientalis. This study takes Platycladus orientalis, one of the main tree species in Mount Tai, as the research object, and studies the natural regeneration of Platycladus orientalis plantations, the growth distribution characteristics of seedlings and the intraspecies relationship, focusing on the role of parent trees on seedling growth, to achieve the purpose of optimizing the structure of Platycladus orientalis, promoting natural regeneration, and further developing the sustainable management of Taishan forest.

\section{Materials and Methods}

\subsection{Study Area}

Mount Tai has significant topographical differences and large undulating slopes. The highest altitude is $1545 \mathrm{~m}$. Mount Tai has obvious differences in landforms. The climate of Mount Tai is a warm temperate continental monsoon climate, with an average annual temperature of $6.0^{\circ} \mathrm{C}$. The annual average temperature at the top of the mountain is $5.3^{\circ} \mathrm{C}$, and the average annual temperature at the bottom of the mountain is $12.8^{\circ} \mathrm{C}$. The average annual precipitation is 1031.3 $\mathrm{mm}$. The rain and heat are in the same season. The soil types mainly include mountain meadow soil, brown soil, and cinnamon soil. Brown soil is the most common. The soil of Mount Tai has obvious vertical and upward changes from bottom to top. The thickness of the soil layer is about $30-40 \mathrm{~cm}$, and the slope is generally around $15^{\circ}-25^{\circ}$.

\subsection{Research Methods}

In May, 2019, a plot of Platycladus orientalis forest was selected and a sample plot was set up for investigation. The research site is located in a pure Platycladus forest near Longtan Reservoir of Taishan Forest Farm, with an altitude of $449-457 \mathrm{~m}$. The geographical coordinate is $36^{\circ} 13^{\prime} 0^{\prime \prime} \mathrm{N}$ and $117^{\circ} 5^{\prime} 48^{\prime \prime} \mathrm{E}$ (Figure 1). The size of the sample plot is $20 \mathrm{~m} * 30 \mathrm{~m}$, and the slope direction is the southwest slope.

We investigated the seedling plant number, ground diameter, seedling height, and tree height, diameter at breast height (DBH), crown width and coordinate of each Platycladus orientalis trees and its seedling regeneration. Monte Carlo stochastic simulation is used to calculate the $99 \%$ confidence interval. In univariate analysis, when $\mathrm{g}(\mathrm{r})$ is higher than the upper envelope, it is aggregated distribution, and $g(r)$ between the upper and lower envelope is a random distribution, 


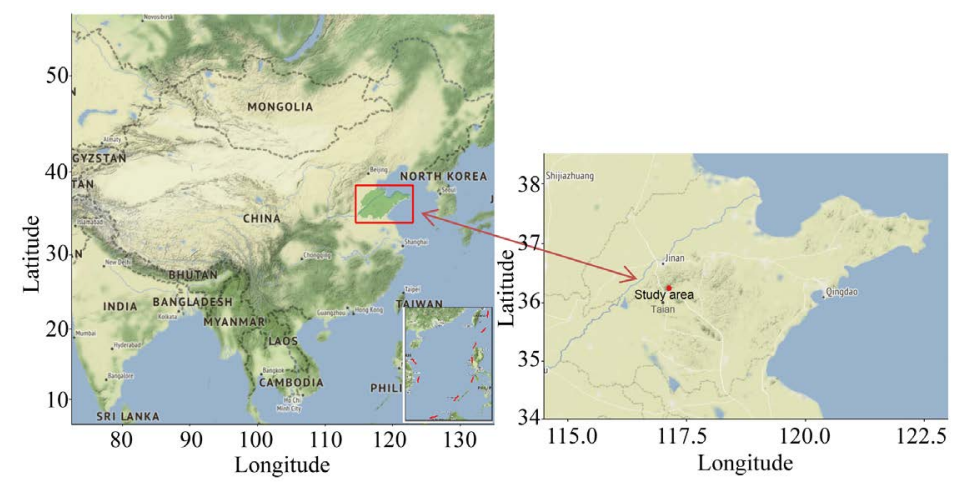

Figure 1. The location of study area and sample.

and $g(r)$ lower than the lower envelope is evenly distributed; In the bivariate analysis, when $g(r)$ is higher than the upper envelope, the two types of patterns are significantly positively correlated, there is no correlation between the upper and lower envelope, and the lower envelope is a significant negative correlation. The point pattern and spatial correlation analysis is conducted by the spatstat software package in R software.

\section{Results}

\subsection{Analysis of Diameter Structure of Platycladus orientalis}

Table 1 shows the statistics of the number of naturally renewed seedlings in the forest. There are a total of 213 cypress seedlings in the plot, 41 plants with a ground diameter of less than $0.5 \mathrm{~cm}$, accounting for 19.2\%; The number of plants between $0.5-1 \mathrm{~cm}$ in diameter is 56 , accounting for $26.3 \%$; the number of plants between $1-2 \mathrm{~cm}$ is 67 , accounting for $31.5 \%$; The number of plants between $2-3 \mathrm{~cm}$ is 24 , accounting for $11.3 \%$; the number of plants between $3-4$ $\mathrm{cm}$ is 14 , accounting for $6.6 \%$; there are 11 plants between $4 \mathrm{~cm}-9 \mathrm{~cm}$, accounting for $5.2 \%$.

It can be seen that the ground diameter of Platycladus orientalis seedlings is mostly distributed below $2 \mathrm{~cm}$. When the ground diameter increases, the number of plants shows a downward trend (Figure 2(a)). In addition, the ground diameter of Platycladus orientalis seedlings rarely exceeds $5 \mathrm{~cm}$, and the number of young trees reaching the starting DBH level $(1 \mathrm{~cm})$ is very few, indicating that natural regeneration is difficult to form a stable forest.

\subsection{Analysis of the Height Structure of Platycladus orientalis}

Table 2 shows the regeneration seedling height of Platycladus orientalis in the sample plot. It can be seen that the number of seedlings decreases with the increase of seedling height (Figure 2(b)). The number of $0.2 \mathrm{~m}-0.4 \mathrm{~m}$ plants is 42, accounting for 19.7\%; 73 plants from $0.4-0.6 \mathrm{~m}$, accounting for 34.3\%; 46 plants from $0.6-0.8 \mathrm{~m}$, accounting for $21.6 \%$; 36 plants from 0.8 to $1.8 \mathrm{~m}$, mainly distributed at $0.8-1 \mathrm{~m}$ and $1.6 \mathrm{~m}$, accounting for $17.6 \%$; The number of plants around $2 \mathrm{~m}$ is 13 , accounting for $6.4 \%$; and there are 3 plants larger than $2 \mathrm{~m}$ 


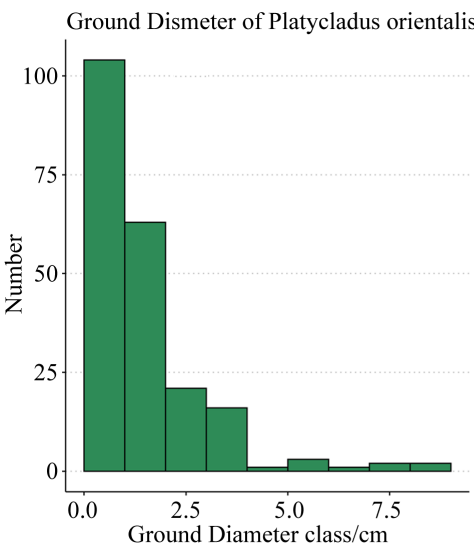

(a)

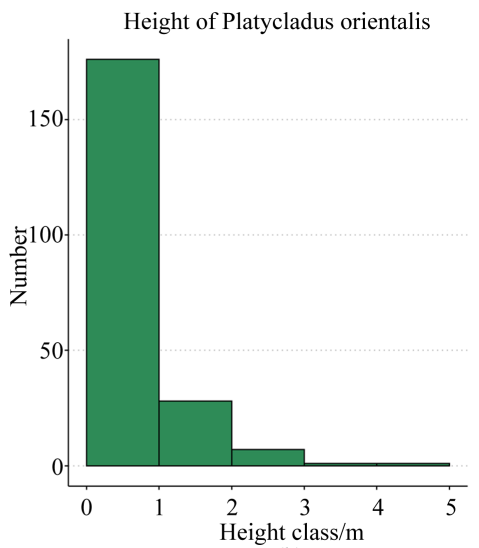

(b)

Figure 2. Population structures of Platycladus orientalis.

Table 1. Ground diameter distribution of Platycladus orientalis seedlings.

\begin{tabular}{ccc}
\hline Ground diameter/cm & Number & Percentage \\
\hline$<0.5$ & 41 & $19.2 \%$ \\
0.5 & 56 & $26.3 \%$ \\
1 & 67 & $31.5 \%$ \\
2 & 24 & $11.3 \%$ \\
3 & 14 & $6.6 \%$ \\
4 & 2 & $0.9 \%$ \\
5 & 4 & $1.9 \%$ \\
6 & 1 & $0.5 \%$ \\
7 & 2 & $0.9 \%$ \\
9 & 2 & $0.9 \%$ \\
\hline
\end{tabular}

Table 2. Height distribution of Platycladus orientalis seedlings.

\begin{tabular}{ccc}
\hline Height/m & Number & Percentage \\
\hline 0.2 & 42 & $19.7 \%$ \\
0.4 & 73 & $34.3 \%$ \\
0.6 & 46 & $21.6 \%$ \\
0.8 & 8 & $3.8 \%$ \\
1 & 9 & $4.2 \%$ \\
1.2 & 1 & $0.5 \%$ \\
1.4 & 3 & $1.4 \%$ \\
1.6 & 8 & $3.8 \%$ \\
1.8 & 7 & $3.3 \%$ \\
2 & 13 & $6.1 \%$ \\
3 & 1 & $0.5 \%$ \\
4 & 2 & $0.9 \%$ \\
\hline
\end{tabular}


and smaller than $4 \mathrm{~m}$, accounting for $1.5 \%$. The number of plants increased from 0.2 to $0.6 \mathrm{~m}$, and showed a downward trend from $0.6 \mathrm{~m}$ to $1.2 \mathrm{~m}$. There was a slight increase in the interval from $1.4 \mathrm{~m}$ to $2 \mathrm{~m}$, and then began to decrease.

\subsection{Analysis of the Spatial Pattern of Platycladus orientalis}

The point pattern analysis method is based on the coordinate value of the individual plant species in space. The individual plant species can be regarded as a point in two-dimensional space in space. In other words, each plant in the sample constitutes a dot map of spatial distribution. The spatial pattern of forest trees will not only vary from species to species, but also behave differently at different growth stages and different age levels. This is closely related to the natural thinning process and environmental changes of forest communities. And the spatial change of environmental conditions causes individuals of the same age to have different distribution patterns at different scales [7].

Figure 3 exhibits the coordinate positions of the parent trees and seedlings in the plot, showing the distributions of cypress parent trees and seedlings inside the plot are clusters. Figure 4 and Figure 5 are univariate point pattern analysis

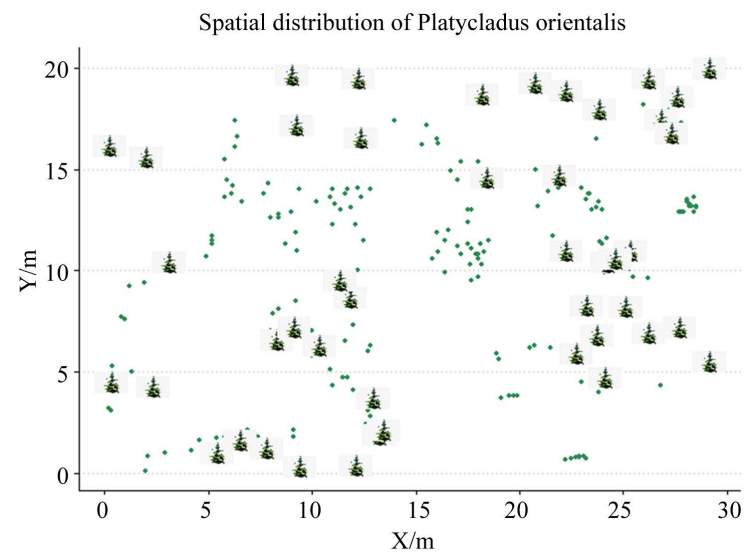

Figure 3. Spatial distributions of Platycladus orientalis.

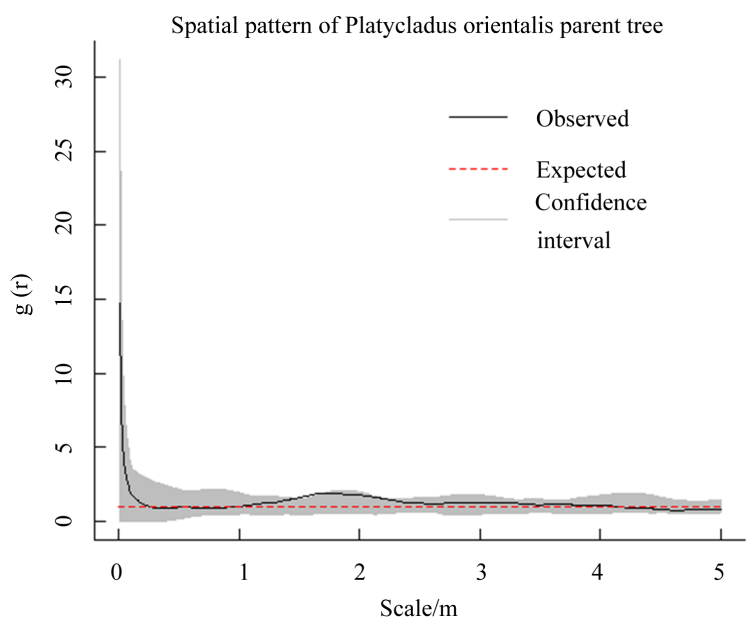

Figure 4. Spatial pattern of Platycladus orientalis parent trees. 


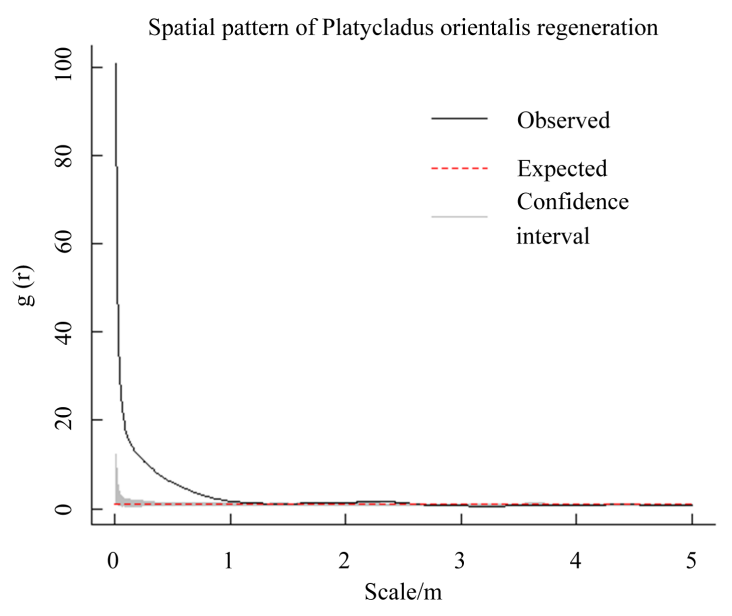

Figure 5. Spatial pattern of Platycladus orientalis seedlings.

of the parent trees and the seedling. Observing the pattern analysis of the parent trees of Platycladus orientalis (Figure 4), it can be seen that the parent trees are randomly distributed with the scale of 0 to $5 \mathrm{~m}$. Observing the pattern map of understory regeneration points in Figure 5, it can be seen that the overall decline is slow at the scale of 0 to $5 \mathrm{~m}$, and the seedlings are clustered at the scale of 0 to $1 \mathrm{~m}$; It showed a random distribution at the scale of $2 \mathrm{~m}-5 \mathrm{~m}$.

According to the above analysis, it can be found that the distribution of the overall point pattern of Platycladus orientalis in the plot is biased towards aggregation distribution and random distribution. Most of the aggregation intensity tends to decrease first, then slowly increase, with slight fluctuations, and generally relatively gentle.

\subsection{Analysis of the Spatial Relationship between Parent Trees and Young Tree}

The distribution pattern of individuals in the same population at different developmental stages is not necessarily the same, and it will change regularly over time [8]. This dynamic and regular change will occur under the influence of environmental factors. Ripley's K-function analysis method can simultaneously analyze spatial distribution patterns at any scale [9]. In the process of seedling growth, in addition to soil, climate, hydrology, slope, aspect and other factors that have an impact on the regeneration and growth of seedlings, the influence of the parent trees itself on the seedlings is also crucial. Analyzing the impact of the parent trees on the seedlings will help regulate the structure of the parent trees, promote natural regeneration, and make the forest stand's self-regeneration ability.

Figure 6 is an analysis of the spatial relationship between Platycladus orientalis parent trees and seedlings inside the plot. Observing the curve in Figure 6, it can be found that the trend is very flat, with a positive correlation and a sharp decline at the scale of 0 to $0.5 \mathrm{~m}$, indicating that the parent tree had a promoting effect on the seedlings at the scale of 0 to $0.5 \mathrm{~m}$. It showed a gentle decline at the 


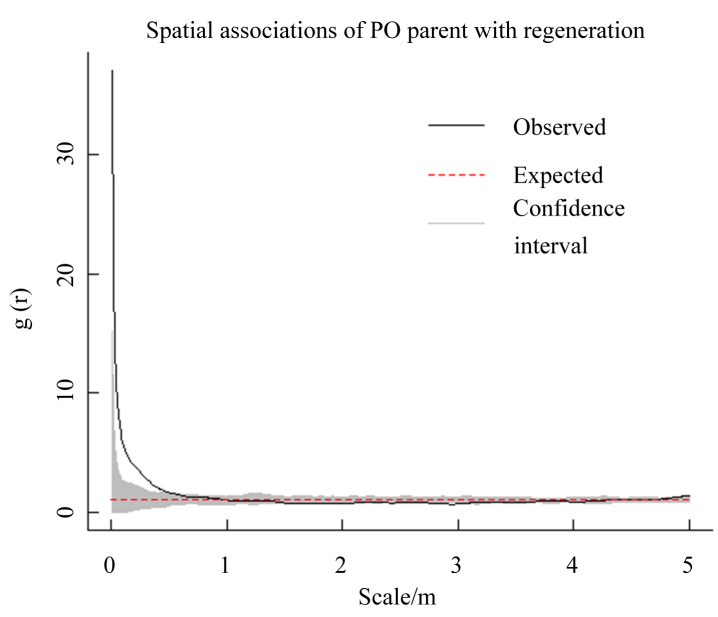

Figure 6. Spatial associations of Platycladus orientalis parent with regeneration.

scale of $0.5 \mathrm{~m}$ to $5 \mathrm{~m}$, it implied that the parent trees and the seedling are independent of each other in the remaining scale range, and there is no inhibition of the seedling by the parent trees in the plot.

\section{Discussion}

\subsection{The Growth and Distribution of the Parent Trees and Seedlings of Platycladus orientalis}

The total number of naturally regenerated seedlings in this plot is abundant, but the growth of seedlings is not realistic. The number of plants decreases sharply with the increase of height and ground diameter. This is in line with the previous investigation on the distribution of Platycladus orientalis seedlings. Platycladus orientalis has good natural regeneration ability, but the seedlings will always die in large numbers after 2 years. There are many reasons why seedlings cannot grow into saplings. The soil in the surveyed plots is relatively thin, with $40 \%$ exposed rocks distributed, and there are few types of ground cover plants, most of which are vitex or wormwood. The height is generally not more than $50 \mathrm{~cm}$, and the coverage degree is low, about $50 \%$ on average, the thickness of the surface humus is $6 \mathrm{~cm}$, and the seedlings and parent trees of Platycladus orientalis are mostly distributed in the crevices of rocks and around rocks. Although Platycladus orientalis has shallow roots and is more tolerant to the environment, insufficient space and poor site conditions still limit the healthy growth of seedlings.

\subsection{Spatial Pattern and Spatial Relationship between the Parent Trees and Seedling of Platycladus orientalis}

1) The parent trees of Platycladus orientalis show a random distribution at a large scale. The seedlings of Platycladus orientalis have a large degree of clustered distribution at a $0-0.5 \mathrm{~m}$ scale. At a large scale, they tend to be distributed randomly. However, all parent trees and seedlings in the entire sample plot showed an aggregated distribution at a large scale. Aggregation distribution pat- 
tern is a very common natural plant distribution pattern, and aggregation distribution is conducive to better exerting group effect [10]. Although the results obtained from the analysis of this study are basically random distribution on large scales, and only small scale distributions are clustered distributions, but for the entire population of Platycladus orientalis, it is still conducive to the qualitative and stable maintenance of the population. There are many influencing factors on the spatial distribution of forest trees, such as the competitive relationship between species and species, the interference of other vegetation on the forest land on the main tree species, the restriction of the biological density on the forest land, the influence of site conditions and so on [7]. The problem faced by the sample plot used in this study lies in the harsh site conditions. In addition, there are many large rocks scattered in the plot, which restricts the survival of Platycladus orientalis. In addition to the topographical influence, according to the coordinate map of the parent trees and the seedlings, it can be basically seen that the Platycladus orientalis plants are clustered distributed.

2) Analyzing the spatial relationship between the parent trees and the seedling of Platycladus orientalis, it can be seen that the parent trees have a promoting effect on the seedling at a small scale, and the parent trees and the seedling are independent of each other at a large scale. Similarly, the spatial relationship between the parent trees of Platycladus orientalis and its seedlings is not only affected by the characteristics of the forest, but also by the spatial location. This also further shows that the spatial distribution pattern of aggregation has a beneficial effect on the survival and development of organisms in the population. The gathering of seedlings around the parent trees is conducive to the initial stage of understory regeneration. However, at the later stage of regeneration, when the seedlings have grown, there will be more intense intraspecific competition, due to the excessive distribution and insufficient living space, which will inevitably occur during the competition. A large number of seedling deaths occur, which is not helpful to the later development of natural regeneration.

Through the analysis of the spatial pattern, it can be concluded that within the species, the aggregation distribution pattern is conducive to seed germination and early growth. Under barren site conditions, the land and crevices around the parent trees and the rocks are more suitable for seedlings to survive, but the subsequent impact of aggregation and distribution is to increase intraspecific competition, making it difficult for natural regeneration to succeed.

\section{Conclusion}

Although there are a large number of seedlings, there are very few regeneration trees that grow healthy to the level of saplings. The seedlings of Platycladus orientalis often begin to die in a large amount when they grow after two years. Although the stability of the community can be temporarily maintained, this situation is not optimistic for long-term development. It is difficult for Platycladus orientalis to grow healthily and sustainably relying on natural fertility. Thus, 
it is very necessary to take correct measures to promote natural regeneration under the artificial forest. It's necessary to thin the forest stands in time to prevent old trees from inhibiting the growth of saplings and causing large areas of death, so that the light conditions in the forest can be improved to facilitate the growth of young trees in future.

\section{Recommendation}

The problem in this investigation and research is insufficient sample data, and this research on the regeneration of Platycladus orientalis did not conduct detailed investigations on various site factors, which can be improved in the future research.

\section{Acknowledgements}

We would like to thank the financial support of Shandong Province Higher School Science and Technology Plan Project (NO. J16LF09), and Shandong Province Natural Science Foundation (NO. ZR2018PC006).

\section{Conflicts of Interest}

The authors declare no conflicts of interest regarding the publication of this paper.

\section{References}

[1] Vergarechea, M., Del Río, M., Gordo, J., Martín, R., Cubero, D. and Calama, R. (2019) Spatio-Temporal Variation of Natural Regeneration in Pinus pinea and Pinus pinaster Mediterranean Forests in Spain. European Journal of Forest Research, 1-14. https://doi.org/10.1007/s10342-019-01172-8

[2] Rezende, G.M. and Vieira, D.L.M. (2019) Forest Restoration in Southern Amazonia: Soil Preparation Triggers Natural Regeneration. Forest Ecology and Management, 433, 93-104. https://doi.org/10.1016/j.foreco.2018.10.049

[3] Soto, D.P. and Puettmann, K.J. (2018) Topsoil Removal through Scarification Improves Natural Regeneration in High-Graded Nothofagus Old-Growth Forests. Journal of Applied Ecology, 55, 967-976. https://doi.org/10.1111/1365-2664.12989

[4] Szwagrzyk, J., Gazda, A., Dobrowolska, D., Chećko, E., Zaremba, J. and Tomski, A. (2018) Natural Regeneration Following Wind Disturbance Increases the Diversity of Managed Lowland Forests in NE Poland. Journal of Vegetation Science, 29 898-906. https://doi.org/10.1111/jvs.12672

[5] Hooper, E.R., Legendre, P. and Condit, R. (2004) Factors Affecting Community Composition of Forest Regeneration in Deforested, Abandoned Land in Panama. Ecology, 85, 3313-3326. https://doi.org/10.1890/03-0655

[6] Pillay, T. and Ward, D. (2012) Spatial Pattern Analysis and Competition between Acacia karroo Trees in Humid Savannas. Plant Ecology, 213, 1609-1619. https://doi.org/10.1007/s11258-012-0115-4

[7] Druckenbrod, D.L., Shugart, H.H. and Davies, I. (2005) Spatial Pattern and Process in Forest Stands within the Virginia Piedmont. Journal of Vegetation Science, 16, 37-48. https://doi.org/10.1111/j.1654-1103.2005.tb02336.x 
[8] Ulrich, W. and Gotelli, N.J. (2010) Null Model Analysis of Species Associations Using Abundance Data. Ecology, 91, 3384-3397. https://doi.org/10.1890/09-2157.1

[9] Picard, N., Bar-Hen, A., Mortier, F. and Chadœuf, J. (2009) The Multi-Scale Marked Area-Interaction Point Process: A Model for the Spatial Pattern of Trees. Scandinavian Journal of Statistics, 36, 23-41. https://doi.org/10.1111/j.1467-9469.2008.00612.x

[10] Wiegand, T., Gunatilleke, S., Gunatilleke, N. and Okuda, T. (2007) Analyzing the Spatial Structure of a Sri Lankan Tree Species with Multiple Scales of Clustering. Ecology, 88, 3088-3102. https://doi.org/10.1890/06-1350.1 